Scientia Agricola

http://dx.doi.org/10.1590/0103-9016-2015-0087

\title{
Evaluation of natural preservatives in combination with acid whey for use in
}

\section{fermented sausage}

\author{
Karolina Maria Wójciak*, Zbigniew Józef Dolatowski
}

University of Life Sciences in Lublin - Dept. of Meat Technology and Food Quality, 8 Skromna - 20-704 - Lublin Poland.

*Corresponding author <karolina.wojciak@up.lublin.pl>

Edited by: Paulo Cesar Sentelhas

\begin{abstract}
Natural antioxidant and antimicrobial systems are set to become an important component in food preservation methodology. The effect of alternative natural preservatives (Sinapis alba L.-M, Rosmarinus officinalis L.-R, Juniperus communis L.-J) in combination with acid whey (AW) was investigated after the ripening period (21d) and over a prolonged storage period of sausage. An antioxidant activity of extracts exercise was performed. The antimicrobial, oxidative stability and sensory properties of these natural preservatives were compared to curing-control (C). Significantly lower rancid odor and rancid flavor (1.48) were observed for $\mathrm{R}$ and $\mathrm{M}$ compared with the $\mathrm{C}$ sample. The low level of these attributes evidenced the antioxidant properties of the $\mathrm{R}$ sample, which confirmed the lower CD ( 0.48-0.48 $\left.\mu \mathrm{mol} \mathrm{mg}^{-1}\right)$ and TBARS values ( 0.41-1.02 mg MDA kg-1) during sausage storing and the highest antioxidant activity against ABTS+ radicals ( $85.45 \%)$. Incorporation of acid whey with rosemary extract will give the product a threefold effect: high quality (sensory acceptance), healthy benefit (elimination of nitrite and nitrate from meat products) and safety (improved microbiological and oxidative stability).

Keywords: storage in vacuum, juniper, mustard, rosemary
\end{abstract}

2014). Tong et al. (2000) proved that whey proteins have excellent potential as antioxidant additives in foods because they can inhibit lipid oxidation through scavenging free radicals and chelation of pro-oxidative transition metals. Moreover, it was discovered that acid whey can be used effectively to improve microbiological quality without adversely affecting organic sausage quality (Wójciak et al., 2014). However, previous research revealed that the addition of acid whey stabilized color and sensory properties of fermented sausages, but did not affect the oxidative stability (Karwowska et al., 2014).

The purpose of this study was to evaluate alternative natural preservatives rosemary, juniper berries, mustard seed extract in combination with acid whey, in the production of organic fermented sausage. These natural preservatives should have the same or comparable antimicrobial properties, chemical stability (2-thiobarbituric acid reactive substances (TBARS) value, conjugated diene, fatty acids composition) and sensory properties as curing agents in conventionally produced fermented sausage.

\section{Materials and Methods}

Manda et al., 2010; Shah et al., 2014). They showed that rosemary, mustard and juniper berry extracts are rich in polyhenol, terpenoids and vitamins. These substances belong to a group of natural antioxidants. The main compounds responsible for the high antioxidant activities of rosemary extracts are phenol diterpenes (carnosic acid, carnosol, rosmarinic acid) (Hernández-Hernández et al., 2009) and for mustard seed extracts: phenolic acids, phytin (Shah et al., 2014) and biothiols, for example, glutathione, cysteine, c-glutamylcysteine (Manda et al., 2010). Major constituents in the juniper berries extract are $\alpha$-pinene, $\beta$-pinene, myrcene, sabinene, limonene, p-mycene, sesquiterpenes, sugar, phenolics, catechol tannins, flavonoids and proanthocyanins (Lesjak et al.,

\section{Experimental procedures}

Preparation of plant extracts and acid whey - The mustard seed (Sinapis alba), rosemary (Rosmarinus officinalis L.) and juniper berry (Juniperus communis L.) purchased from a local organic plant were applied during the experiment. Ethanol extracts from the dried leaves (rosemary), dried seeds (mustard) and dried berries (juniper) were obtained by macerating the leaves, seeds, and berries. Fifteen grams of finely chopped dried herbs were mixed with $150 \mathrm{~mL}$ of ethanol; the flasks were tightly closed and the chopped dried herbs macerated 
at room temperature (approximately $20^{\circ} \mathrm{C}$ ) for $2 \mathrm{~h}$ in an orbital stirrer at $100 \mathrm{rpm}$. The mixture was then filtered through Whatman 2 filter paper and washed with 150 $\mathrm{mL}$ ethanol; both extracts were combined; the solvent was evaporated and concentrated using a rotavapor at $35{ }^{\circ} \mathrm{C}$. The weighed extract was mixed with a known ethanol volume (for analysis of antioxidant properties) and stored in amber flasks in the dark at $4{ }^{\circ} \mathrm{C}$ until utilization, though, no more than an additional $24 \mathrm{~h}$. The plant extract concentration was chosen according to the results presented by Hernández-Hernández et al. (2009).

Fresh acid whey was obtained from cottage cheese production from the local organic dairy processing plant. The properties of acid whey were presented in a previous manuscript (Wójciak et al., 2014).

Product manufacture and storage - The sausages were prepared from Musculus biceps femoris and pork backfat in the proportion of 85:15 (w/w). The raw materials were purchased at $48 \mathrm{~h}$ post mortem from crossbreds of Puławska X Polish Landrace with a body weight of $125-130 \mathrm{~kg}$ at slaughter. The pork meat was curing $(2.8$ $\%)$ or salting $(2.8 \%)$ and being stored at $2{ }^{\circ} \mathrm{C}$ for $24 \mathrm{~h}$. The raw materials were ground through a $10 \mathrm{~mm}$ plate and mixed with additives. Five batches were prepared: (1) control with the curing mixture $-2.8 \% \mathrm{w} / \mathrm{w}$ (extract/ batter) $(\mathrm{C})$ and water $(5 \%)$ added; (2) salted $(2.8 \%)$ control with acid whey added - $5 \%$ (AW); (3) salted $(2.8 \%)$ with acid whey $(4.97 \%)$ and mustard seed extract $(0.03$ $\%)$ added $(\mathrm{M}) ;(4)$ salted $(2.8 \%)$ with acid whey $(4.97 \%)$ and rosemary extract $(0.03 \%)$ added $(\mathrm{R}) ;(5)$ salted $(2.8$ $\%)$ with acid whey (4.97\%) and juniper berry extract $(0.03 \%)$ added $(\mathrm{J})$. The mixes were stuffed into fibrous casings $(65 \mathrm{~mm})$ and matured under the following conditions: $18-19{ }^{\circ} \mathrm{C}$ and relative humidity between $75-80 \%$ for 21 days. After five days of maturation, the sausages were cold-smoked for $1 \mathrm{~h}$ at $26{ }^{\circ} \mathrm{C}$ with oak-alder wood chips. Following maturation, the sausages were vacuum packed and stored in a refrigerator (at $4{ }^{\circ} \mathrm{C}$ ) for 180 days. The first sample corresponds to the day immediately after maturation (day 0), and the following samples after 90 and 180 days of chilling storage. At maturation the loss of sausage weight was evaluated by comparing the sausage weight before ripening (0) and after 7,14 and 21 days of ripening.

\section{Antioxidant activity analysis}

ABTS radical cation decolorization assay - The antioxidant activity was assayed on the basis of a method presented by Re et al. (1999). Percentage inhibition of the ABTS + radical was then calculated using the equation:

scavenging $\%=\left[1-\left(\mathrm{A}_{\mathrm{s}} / \mathrm{A}_{\mathrm{c}}\right)\right] \times 100$

where: As is the absorbance of sample and Ac is the absorbance of control (ABTS + solution).
Determination of reducing power - The reducing power of the sample was determined by the method described by Oyaizu (1986). The absorbance was read at $700 \mathrm{~nm}$.

\section{Analysis of samples}

pH value and water activity determination - Homogenates were prepared by homogenizing $10 \mathrm{~g}$ of sausage with $50 \mathrm{ml}$ of distilled water for $60 \mathrm{~s}$ using the homogenizer. Readings were taken with a $\mathrm{pH}$ meter fitted with a pH electrode. Water activity (aw) measurements were taken at $20{ }^{\circ} \mathrm{C}$ using a water activity analyzer $L a b$ Master-aw.

Composition of fatty acids - An analysis of fatty acid composition was carried out on total lipids extracted after methyl-esterification following the procedure described in Method 969.33 (AOAC 2005). A gas chromatographic analysis was carried out as described by Official Method 996.06 (AOAC 2000) using a chromatograph equipped with a capillary fused silica column and flame ionization detection was used.

Conjugated dienes analysis - Conjugated dienes (CD) concentrations were determined using a modified method of Karwowska et al. (2014) adopted from Srinivasan et al. (1996). The CD concentration was calculated using a molar extinction coefficient of $25,000 \mathrm{M}^{-1} \mathrm{~cm}^{-1}$, and the results were expressed in terms of $\mu \mathrm{mol} \mathrm{mg}^{-1}$ sample.

Measurements of TBARS value - The extent of lipid oxidation was determined in sausages by measuring the TBA-reactive substances at 0,90 and 180 days of storage following the procedure proposed by Pikul et al. (1989). Values were expressed as $\mathrm{mg}$ of malondialdehyde per kilogram of sample.

Microbial analysis - Twenty grams of roast sample were homogenized with $180 \mathrm{ml}$ of peptone water for one min in a Stomacher Lab- Blender and decimal dilutions were prepared. The population of lactic acid bacteria (LAB) was determined by spread count plating onto MRS agar and incubated anaerobically at $30{ }^{\circ} \mathrm{C}$ for 72 hours. A microbiological test to determine lactic acid bacteria (LAB) was performed according to ISO (2002). For Listeria monocytogenes detection, enrichment was achieved by suspending $25 \mathrm{~g}$ of sample in $225 \mathrm{~mL}$ Fraser broth followed by incubation at $30^{\circ} \mathrm{C}$ for $24 \mathrm{~h}$. Next, $0.1 \mathrm{~mL}$ of the culture enrichment was streaked on PALCAM agar and incubated at $30^{\circ} \mathrm{C}$ for $48 \mathrm{~h}$ according to ISO (2000). The population of Enterobacteriaceae was determined by spread count plating onto VRBG agar and incubated anaerobically at $30{ }^{\circ} \mathrm{C}$ for $48 \mathrm{~h}$ according to ISO (2005). The population of Salmonella was determined according to ISO 6579 (2003). The population of coagulase positive cocci (St. aureus and other strains) count was determined 
according to ISO (1999) part 1 and 2. The counts were expressed as colony forming units $\left(\log \mathrm{cfu} \mathrm{g}^{-1}\right)$.

Quantitative descriptive analysis - QDA was conducted by the same trained sensory panel $(\mathrm{n}=12)$ on the 180th day of chilling storage evaluation according to generic descriptive analysis as described by ISO method (1998). A list of 16 attributes (odor, flavor and visual appearance) was generated during a brainstorming session (Table 1). Attributes were evaluated using an unstructured linear graphical scale; $100 \mathrm{~mm}$ were converted to numerical values (0 -10 conventional units - c.u.) ranging from zero intensity $(0)$ on the left to high intensity (10) on the right. The assessment of the tested samples was made by a 12-person panel. The panel had 3 to 8 years experience in sensory evaluation practice. They were prepared theoretically and practically for the methods applied in this experiment.

Statistical analysis - The experiment was carried out on two samples of raw meat and acid whey and plant extracts in three replications. The mean and standard error (SE) were calculated for each test. The data were analysed by two-way ANOVA to test the treatment effect and time of storage $(0,90,180$ days $)$ using the SAS statistical software. The significance of the differences between mean values was calculated at a significance level of $p<0.05$ using T-Tukey's range test.

\section{Results and Discussion}

\section{Antioxidant activity of plant extracts}

The percentage inhibition of ABTS + radicals by alcohol: rosemary, juniper berry and mustard seed ex- tracts, were $85.45 \pm 1.77,78.03 \pm 3.33$ and $28.45 \pm 1.92$ $\%$ respectively. It should be noted that all samples studied exhibited free radical activities. Studies on ABTS + scavenging ability clearly showed that rosemary extract was significantly more effective $(p<0.05)$ than mustard seed extract. The specific nature of antioxidative compounds in the plant extracts have not been investigated in the present study. However Shah et al. (2014) described that the major antioxidative compounds could have been phenolic compound. Manda et al. (2010) reported that mustard seed also have strong antioxidant activity because of biologically active thiols like glutathione.

The reducing power of alcohol rosemary, juniper berries and mustard seed extracts, were $3.99 \pm 0.24$, $4.78 \pm 0.29$ and $4.32 \pm 0.33$ respectively. The significantly higher ability $(p<0.05)$ to reduce $\mathrm{Fe}(\mathrm{III})$ to $\mathrm{Fe}(\mathrm{II})$ was discovered in a juniper berry extract when compared to a rosemary extract. There were no significant $(p>0.05)$ differences between mustard seed extract compared to other extracts. Reducing power is an extremely important property of plant extracts which are considered a natural antioxidant in meat products. Changes in myoglobin from a ferrous $\left(\mathrm{Fe}^{2+}\right)$ to a ferric $\left(\mathrm{Fe}^{3+}\right)$ state are crucial to meat product appearance, because consumers consider browning (metmyoglobin) as an indicator of spoilage. The presence of metmyoglobin may also have consequences for oxidative stability especially for the unsaturated fatty acids because this ferric state of myoglobin acts as a pro-oxidant (Hernández-Hernández et al., 2009; Zhang et al., 2009). For these reasons the ability to reduce ferric to ferrous state are desirable properties of extracts added to the meat matrix.

Table 1 - Organic sausage attributes, their definitions and boundary terms.

\begin{tabular}{|c|c|c|}
\hline Attribute & Definition & Boundary terms \\
\hline \multicolumn{3}{|l|}{ Odour (Aroma) } \\
\hline Rancid & Odor associated with oxidation compounds derived from fat & none - very strong \\
\hline Metallic & Odor associated with metal, ferrous sulfate $\left(\mathrm{FeSO}_{4}\right)$, iron $(\mathrm{Fe})$ & none - very strong \\
\hline Acid & Intensity of acid odour before eating & none - very strong \\
\hline Spicy & Intensity of spicy odour before eating & none - very strong \\
\hline Overall quality & Attribute of total quality of dry fermented sausage & bad - very good \\
\hline Fat color & Intensity of visible fat color & yellow - white \\
\hline Meat color & Intensity of red color in the product & brown - light pink \\
\hline Part of green color & Intensity of green color in the product & none - very strong \\
\hline Juiciness & Impression of juiciness during chewing & dry - very juicy \\
\hline Compactness of slice & Tactile texture attribute related to the strength of the internal bonds of the structure of the slice & low - very high \\
\hline \multicolumn{3}{|c|}{ (2) } \\
\hline Rancid & Flavor associated with oxidation compounds derived from fat after swallowing & none - very strong \\
\hline Sweet & Intensity sweet taste & none - very strong \\
\hline Metallic & Flavor associated with metal, ferrous sulfate $\left(\mathrm{FeSO}_{4}\right)$, iron $(\mathrm{Fe})$ & none - very strong \\
\hline Acid & Intensity of acid taste & none - very strong \\
\hline Bitter & Intensity of bitter taste & none - very strong \\
\hline Spicy & Intensity of spicy taste & none - very strong \\
\hline
\end{tabular}




\section{Loss of sausage weight}

Figure 1 shows the exponential behavior of the weight loss curves, in which the addition of plant extracts was associated with the highest rate of weight loss (39.5 - $41.2 \%)$ during the drying period, followed by treatment with acid whey $(39.0 \%)$ and the control treatment $(37.6 \%)$, which presented the lowest rate.

From the seventh day of drying onwards, $\mathrm{R}$ and J sausages began to suffer a greater loss of weight than the control, AW and M sausages, and that over the drying period, the $\mathrm{R}$ and J sausages exhibited more rapid weight loss. The sample with acid whey and mustard seed extract (M) experienced weight loss at an intermediate velocity during the drying period. The greater weight loss observed in the samples with acid whey and plant extract addition was related to the increased acidification of the raw sausages, which facilitated the weight loss of the samples. The low $\mathrm{pH}$ is one of the factors that significantly sped up the diffusion of water from the inside to the surface of sausage. The weight loss results were within the range reported by other authors, between 40 and $45 \%$ in Italian salami (Ruiz et al., 2014). After the drying period, the sausages were stored in vacuum packages, preventing gas exchange or a loss of moisture. Hence, weight loss was not determined during storage.

\section{$\mathrm{pH}$ value and water activity determination}

The $\mathrm{pH}$ ANOVA analysis of the sausage showed significant differences between the means of the five treatments, which ranged from 4.87 to 5.16 after production ( 0 day) and from 5.04 to 5.37 after 180 days of storage (Table 2). After maturation, the control had an average $\mathrm{pH}$ of 4.87 , while all the organic treatments had significantly higher average values $(p<0.05)$ from 4.96 to 5.16. After 90 days of storage, the control and two organic samples with rosemary and juniper berry extract had an average $\mathrm{pH}$ of 5.07, while the remaining samples had a significantly higher average $\mathrm{pH}(p<0.05)$ of 5.24. At the end of the storage period significantly

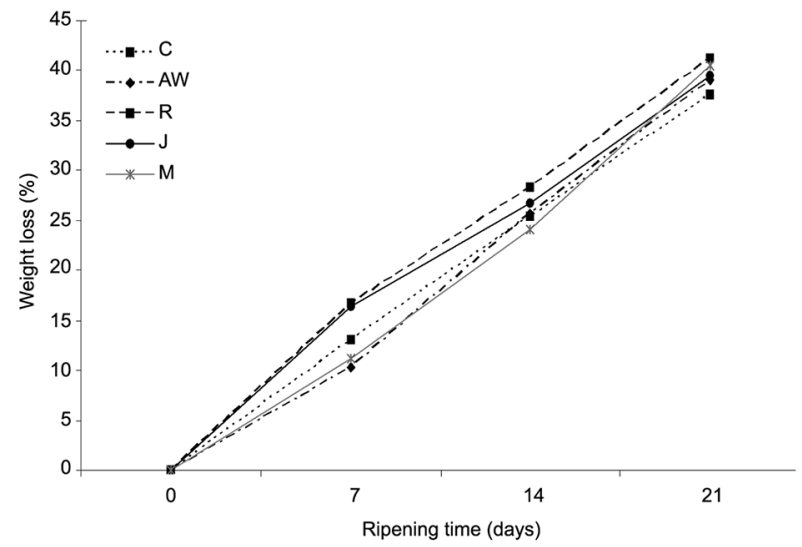

Figure 1 - Weight loss of the organic fermented sausages during 21 days of ripening. $C=$ control, $A W=$ acid whey, $R=$ rosemary, $\mathrm{J}=$ juniper berries, $\mathrm{M}=$ mustard seed. lower $\mathrm{pH}$ values $(p<0.05) \mathrm{pH}$ were observed for $\mathrm{R}$ and J samples compared to other treatments. During 180 days of sausage storage significant increases $(p<0.05)$ were observed for all study samples. Similar results of $\mathrm{pH}$ values, ranging from 4.76 to 5.22 , were reported by Ščetar et al. (2013).

As can be seen in Table 2, water activity values were dropping continually ( $p<0.05$ ) up to 180 days of storage. This is in agreement with water activity measurements which showed no significant differences between all study samples after maturation and after 90 and 180 days of storage period. The $\mathrm{pH}$ values of all the treatments increased $(p<0.05)$ and the water activity decreased $(p<0.05)$ as storage progressed. The increases in $\mathrm{pH}$ value and decreases in water activity indicated production of low molecular weight nitrogen compounds from decomposition of meat protein during storage by meat and microbial enzymes (Marra et al., 1999). Average water activity in dry fermented sausage was similar to that found by Stadnik et al. (2014) for drycured loins. According to Leistner et al. (1981), shelf-stable meat products are classified as those having $\mathrm{pH}$ below 5.0 or water activity at or below 0.95 . According to the results obtained uncured sausages can be considered as shelf-stable at room temperature; however, additional research should be conducted to support this hypothesis.

\section{Composition of fatty acids}

At the end of the ripening process, sums of saturated fatty acids in control sausages and organic sausages rose from 45.44 to $46.90 \%$ (Table 3). These values were not significantly different $(p>0.05)$. However, after 180 days of storage the amount of fatty acids was significantly higher $(p<0.05)$ in the control sausage, compared to organic sausage with acid whey-plant extract combination $(R, J, M)$. These values did not change significantly $(p>0.05)$ during the storage period. There were no sig-

Table 2 - Influence of acid whey with plant extracts combination and storage time on $\mathrm{pH}$ and water activity value (means \pm standard error).

\begin{tabular}{|c|c|c|c|c|}
\hline & \multicolumn{3}{|c|}{ Storage time (day) } \\
\hline & & 0 & 90 & 180 \\
\hline \multirow{5}{*}{ pH } & C & $4.87 \pm 0.05^{\mathrm{aA}}$ & $5.07 \pm 0.05^{\mathrm{aB}}$ & $5.37 \pm 0.05^{\mathrm{ac}}$ \\
\hline & AW & $5.06 \pm 0.02^{\mathrm{bA}}$ & $5.26 \pm 0.02^{\mathrm{bB}}$ & $5.32 \pm 0.03^{a c}$ \\
\hline & $\mathrm{R}$ & $4.99 \pm 0.01^{\mathrm{cA}}$ & $5.04 \pm 0.01^{\mathrm{aB}}$ & $5.20 \pm 0.04^{\mathrm{bc}}$ \\
\hline & J & $4.96 \pm 0.04^{\mathrm{cA}}$ & $5.09 \pm 0.04^{\mathrm{aB}}$ & $5.19 \pm 0.04^{\mathrm{bc}}$ \\
\hline & M & $5.16 \pm 0.04^{\mathrm{dA}}$ & $5.22 \pm 0.01^{\mathrm{bA}}$ & $5.35 \pm 0.04^{\mathrm{aB}}$ \\
\hline \multirow{5}{*}{$a_{w}$} & $C$ & $0.969 \pm 0.001^{\mathrm{aA}}$ & $0.952 \pm 0.003^{a \mathrm{~B}}$ & $0.949 \pm 0.006^{a c}$ \\
\hline & AW & $0.962 \pm 0.002^{\mathrm{aA}}$ & $0.944 \pm 0.004^{\mathrm{aB}}$ & $0.938 \pm 0.003^{\mathrm{aC}}$ \\
\hline & $\mathrm{R}$ & $0.975 \pm 0.001^{\mathrm{aA}}$ & $0.950 \pm 0.005^{\mathrm{aB}}$ & $0.942 \pm 0.004^{\mathrm{ac}}$ \\
\hline & J & $0.972 \pm 0.002^{\mathrm{aA}}$ & $0.956 \pm 0.004^{\mathrm{aB}}$ & $0.944 \pm 0.006^{a B}$ \\
\hline & M & $0.963 \pm 0.002^{\mathrm{aA}}$ & $0.951 \pm 0.005^{\mathrm{aB}}$ & $0.940 \pm 0.003^{\mathrm{ac}}$ \\
\hline
\end{tabular}

Means followed by the same letters within columns (lower case letters) and row (capital letters) are not significantly different at $p<0.05 ; C=$ control. AW $=$ acid whey $. \mathrm{R}=$ rosemary $\mathrm{J}=$ juniper berries. $\mathrm{M}=$ mustard seed; aw - water activity. 
Table 3 - Fatty acid composition (means \pm standard error) of uncured model fermented sausage after 21 days of ripening (0) and 180 days of chilling storage (\%).

\begin{tabular}{|c|c|c|c|c|c|c|}
\hline Fatty acid & Storage (day) & C & AW & $\mathrm{R}$ & J & M \\
\hline \multirow{2}{*}{$16: 0$} & 0 & $27.46 \pm 0.12^{A}$ & $27.88 \pm 0.01^{A}$ & $27.36 \pm 0.08^{A}$ & $27.98 \pm 0.30^{A}$ & $28.01 \pm 0.04^{A}$ \\
\hline & 180 & $29.48 \pm 1.6^{B}$ & $28.95 \pm 1.39^{A}$ & $27.54 \pm 0.28^{A}$ & $28.11 \pm 0.15^{A}$ & $28.24 \pm 0.09^{A}$ \\
\hline \multirow{2}{*}{$16: 1$} & 0 & $2.58 \pm 0.02^{\mathrm{A}}$ & $2.65 \pm 0.05^{A}$ & $2.80 \pm 0.06^{A}$ & $2.69 \pm 0.11^{A}$ & $2.49 \pm 0.56^{A}$ \\
\hline & 180 & $2.45 \pm 0.25^{A}$ & $2.65 \pm 0.27^{A}$ & $2.55 \pm 0.16^{A}$ & $2.78 \pm 0.05^{A}$ & $2.82 \pm 0.02^{A}$ \\
\hline \multirow{2}{*}{ 18:0 } & 0 & $16.56 \pm 0.03^{A}$ & $15.96 \pm 0.24^{A}$ & $14.98 \pm 0.37^{A}$ & $16.08 \pm 0.17^{A}$ & $15.24 \pm 0.04^{\mathrm{A}}$ \\
\hline & 180 & $16.82 \pm 0.64^{A}$ & $15.83 \pm 1.04^{A}$ & $15.85 \pm 0.40^{\mathrm{B}}$ & $15.54 \pm 0.30^{A}$ & $15.48 \pm 0.04^{A}$ \\
\hline \multirow{2}{*}{$18: 1(n-9)$} & 0 & $39.87 \pm 0.00^{A}$ & $40.60 \pm 0.38^{A}$ & $41.35 \pm 0.25^{A}$ & $40.52 \pm 0.16^{A}$ & $40.81 \pm 0.17^{A}$ \\
\hline & 180 & $39.03 \pm 0.89^{A}$ & $40.29 \pm 0.24^{A}$ & $41.21 \pm 0.25^{A}$ & $40.42 \pm 0.21^{A}$ & $40.47 \pm 0.14^{\mathrm{A}}$ \\
\hline \multirow{2}{*}{$18: 2(n-6)$} & 0 & $7.98 \pm 0.08^{A}$ & $7.28 \pm 0.45^{A}$ & $7.66 \pm 0.06^{A}$ & $7.13 \pm 0.04^{A}$ & $7.30 \pm 0.08^{A}$ \\
\hline & 180 & $6.91 \pm 0.86^{B}$ & $6.69 \pm 1.51^{\mathrm{A}}$ & $7.28 \pm 0.15^{A}$ & $7.40 \pm 0.35^{A}$ & $7.33 \pm 0.11^{\mathrm{A}}$ \\
\hline \multirow{2}{*}{$18: 3(n-3)$} & 0 & $0.79 \pm 0.02^{A}$ & $0.69 \pm 0.06^{A}$ & $0.81 \pm 0.01^{\mathrm{A}}$ & $0.68 \pm 0.00^{A}$ & $0.74 \pm 0.02^{A}$ \\
\hline & 180 & $0.59 \pm 0.11^{\mathrm{A}}$ & $0.61 \pm 0.25^{A}$ & $0.71 \pm 0.03^{A}$ & $0.74 \pm 0.08^{A}$ & $0.76 \pm 0.04^{A}$ \\
\hline \multirow{2}{*}{$20: 1$} & 0 & $1.14 \pm 0.01^{\mathrm{A}}$ & $1.22 \pm 0.01^{A}$ & $1.15 \pm 0.01^{A}$ & $1.24 \pm 0.05^{\mathrm{A}}$ & $1.20 \pm 0.00^{A}$ \\
\hline & 180 & $1.19 \pm 0.01^{\mathrm{A}}$ & $1.22 \pm 0.14^{\mathrm{A}}$ & $1.20 \pm 0.01^{\mathrm{A}}$ & $1.20 \pm 0.04^{\mathrm{A}}$ & $1.18 \pm 0.03^{\mathrm{A}}$ \\
\hline \multirow{2}{*}{ SFA } & 0 & $46.90 \pm 0.11^{A}$ & $46.77 \pm 0.17^{A}$ & $45.44 \pm 0.42^{A}$ & $46.99 \pm 0.16^{A}$ & $46.30 \pm 0.11^{\mathrm{A}}$ \\
\hline & 180 & $49.01 \pm 2.19^{\mathrm{B}}$ & $47.64 \pm 2.20^{A}$ & $46.11 \pm 0.56^{A}$ & $46.56 \pm 0.28^{A}$ & $46.58 \pm 0.01^{A}$ \\
\hline \multirow{2}{*}{ MUFA } & 0 & $43.93 \pm 0.01^{A}$ & $44.88 \pm 0.34^{A}$ & $45.70 \pm 0.33^{A}$ & $44.82 \pm 0.11^{\mathrm{A}}$ & $45.29 \pm 0.19^{A}$ \\
\hline & 180 & $43.02 \pm 1.19^{A}$ & $44.57 \pm 0.39^{A}$ & $45.36 \pm 0.40^{A}$ & $44.79 \pm 0.18^{A}$ & $44.83 \pm 0.15^{A}$ \\
\hline \multirow{2}{*}{ PUFA } & 0 & $9.16 \pm 0.11^{A}$ & $8.33 \pm 0.52^{A}$ & $8.85 \pm 0.08^{A}$ & $8.17 \pm 0.06^{A}$ & $8.38 \pm 0.09^{A}$ \\
\hline & 180 & $7.90 \pm 1.01^{\mathrm{B}}$ & $7.71 \pm 1.89^{\mathrm{B}}$ & $8.46 \pm 0.18^{A}$ & $8.58 \pm 0.45^{A}$ & $8.52 \pm 0.14^{A}$ \\
\hline \multirow{2}{*}{ OMEGA3 } & 0 & $0.79 \pm 0.02^{A}$ & $0.69 \pm 0.06^{A}$ & $0.81 \pm 0.01^{A}$ & $0.68 \pm 0.00^{A}$ & $0.74 \pm 0.02^{A}$ \\
\hline & 180 & $0.59 \pm 0.11^{\mathrm{A}}$ & $0.61 \pm 0.25^{A}$ & $0.71 \pm 0.03^{A}$ & $0.74 \pm 0.08^{A}$ & $0.76 \pm 0.04^{A}$ \\
\hline \multirow{2}{*}{ OMEGA6 } & 0 & $7.98 \pm 0.08^{A}$ & $7.28 \pm 0.45^{A}$ & $7.66 \pm 0.06^{A}$ & $7.13 \pm 0.04^{A}$ & $7.30 \pm 0.08^{A}$ \\
\hline & 180 & $6.91 \pm 0.86^{\mathrm{B}}$ & $6.71 \pm 1.54^{\mathrm{A}}$ & $7.28 \pm 0.15^{A}$ & $7.40 \pm 0.35^{A}$ & $7.33 \pm 0.11^{\mathrm{A}}$ \\
\hline
\end{tabular}

Means followed by the same letters within columns (lower case letters) and row (capital letters) are not significantly different at $p<0.05$; SFA $=$ saturated fatty acids; MUFA = monounsaturated fatty acids; PUF = polyunsaturated fatty acids; $\mathrm{P} / \mathrm{S}=$ polyunsaturated fatty acids $/$ saturated fatty acids; $\mathrm{C}=\mathrm{control} ; \mathrm{AW}=\mathrm{acid}$ whey; $\mathrm{R}=$ rosemary,; $\mathrm{J}=$ juniper berries; $M$ = mustard seed.

nificant differences $(p>0.05)$ in the content of MUFA and PUFA between the sausages investigated neither at the end of the ripening process nor during the storage period. SFA, MUFA, PUFA, OMEGA3 and OMEGA6 contents did not differ significantly $(p>0.05)$ during the storage period except for sausages enriched in acid whey-plant extract mixture. The results obtained are likely caused by the good oxidative stability of uncured sausage $(R, J, M)$ during the storage period. Similar results were also achieved by Šojić et al. (2014). Decreases were observed in LPUFA, which have greater susceptibility to oxidation. This decrease was more pronounced in the control sausages, indicating higher oxidation.

\section{Conjugated dienes and TBARS values analysis}

Controlling lipid oxidation is crucial to ensuring safety in meat products, as some lipid oxidation products such as hexanal, pentanal, 2,4-decadienal, 2-octenal appear to have carcinogenic and mutagenic properties (Poli et al., 2009). Table 4 shows the influence of acid whey with plant extract combination and storage time on primary (conjugated diene) and secondary (TBARS values) lipid oxidation products of sausages. Only one treatment had a lower concentration of CD compared to control with curing salt on the first day after maturation, namely a sample with rosemary extract and acid whey addition ( $0.40 \mu \mathrm{mol} \mathrm{mg}^{-1}$ ). After 90 and 180 days of storage no significant differences were observed in CD concentration between all the study treatments. The formation of CD increased $(p<0.05)$ for all the study samples progressively during the entire storage period. These results agree with those reported by other authors (Lee et al., 2010; Karwowska et al., 2014). In all the study samples, except for $\mathrm{C}$ and $\mathrm{AW}$, significant $(p<0.05)$ increases in CD values were observed after 90 days of storage.

All organic samples with AW and plant extract addition were characterized by higher TBARS values, from 0.61 to $1.3 \mathrm{mg} \mathrm{MDA} \mathrm{kg}{ }^{-1}$, compared with the curing sample during the entire storage period. An exception was a sample with rosemary extract and acid whey (R). The sample (R) appeared to be comparable in effectiveness to control with nitrite $(p>0.05)$. Similar value of TBARS was found by $\mathrm{Li}$ et al. (2013) after 28 days of dry-cured sausages enriched with plant polyphenols ripening. Several authors indicated the antioxidant activity of whey proteins in food matrix (Tong, 2000; Shon and Haque, 2007). However, the effectiveness of liquid acid whey in retarding lipid oxidation in fermented meat products was poor (Karwowska et al., 2014). Karwowska et al. (2014) and Wójciak et al. (2014) proved that the addition of native and autoclaved mustard seed with a combination of AW improved the lipid stability of the organic free model sausage during vacuum storage. 
Table 4 - Influence of acid whey with plant extract combination and storage time on conjugated diene ( $\mu \mathrm{mol} \mathrm{mg}^{-1}$ ), and TBARS values (mg MDA $\mathrm{kg}^{-1}$ ) (means \pm standard error).

\begin{tabular}{lcccc}
\hline & & \multicolumn{3}{c}{ Storage time (day) } \\
\cline { 3 - 5 } & & 0 & 90 & 180 \\
\hline Conjugated diene & $\mathrm{C}$ & $0.41 \pm 0.02^{\mathrm{aA}}$ & $0.42 \pm 0.05^{\mathrm{aA}}$ & $0.42 \pm 0.03^{\mathrm{aA}}$ \\
$\left(\mu \mathrm{mol} \mathrm{mg}^{-1}\right)$ & $\mathrm{AW}$ & $0.42 \pm 0.03^{\mathrm{aA}}$ & $0.49 \pm 0.09^{\mathrm{aA}}$ & $0.55 \pm 0.03^{\mathrm{bB}}$ \\
& $\mathrm{R}$ & $0.40 \pm 0.02^{\mathrm{aA}}$ & $0.49 \pm 0.02^{\mathrm{aB}}$ & $0.48 \pm 0.03^{\mathrm{aB}}$ \\
& $\mathrm{J}$ & $0.31 \pm 0.04^{\mathrm{bA}}$ & $0.49 \pm 0.05^{\mathrm{aB}}$ & $0.47 \pm 0.03^{\mathrm{aB}}$ \\
& $\mathrm{M}$ & $0.37 \pm 0.03^{\mathrm{abA}}$ & $0.43 \pm 0.02^{\mathrm{aB}}$ & $0.51 \pm 0.02^{\mathrm{aC}}$ \\
\hline TBARS values (mg MDA kg-1) & $\mathrm{C}$ & $0.39 \pm 0.08^{\mathrm{aA}}$ & $0.92 \pm 0.06^{\mathrm{aB}}$ & $1.13 \pm 0.03^{\mathrm{aC}}$ \\
& $\mathrm{AW}$ & $1.49 \pm 0.30^{\mathrm{bCA}}$ & $1.69 \pm 0.07^{\mathrm{bA}}$ & $1.80 \pm 0.07^{\mathrm{bA}}$ \\
& $\mathrm{R}$ & $0.41 \pm 0.09^{\mathrm{aA}}$ & $1.04 \pm 0.07^{\mathrm{aB}}$ & $1.02 \pm 0.05^{\mathrm{aB}}$ \\
& $\mathrm{J}$ & $1.69 \pm 0.0^{\mathrm{CA}}$ & $1.89 \pm 0.10^{\mathrm{cA}}$ & $1.87 \pm 0.17^{\mathrm{bA}}$ \\
\hline
\end{tabular}

Means followed by the same letters within columns (lower case letters) and row (capital letters) are not significantly different at $p<0.05 ; \mathrm{C}=\mathrm{control}$, AW $=$ acid whey, $\mathrm{R}=$ rosemary, $\mathrm{J}$ = juniper berries, $\mathrm{M}=$ mustard seed.

\section{Microbial analysis}

The major food borne pathogens that are predominant and involved in the spoilage of fermented meat product are: L. monocytogenes, Salmonella, S. aureus, Enterobacteriaceae, and E. coli. The number of Lactic Acid Bacteria, coagulase positive cocci, Salmonella and L. monocytogenes are presented in Table 5. In all study samples the microflora was dominated by LAB. The count of LAB in all samples after ripening was on the level of 7.51-7.64 $\log \mathrm{cfu} \mathrm{g}^{-1}$. After 180 days of storage the count of LAB in samples $\mathrm{J}$ and $\mathrm{M}$ was lower by approximately one logarithmic level than after ripening. It is not surprising that sausage with juniper berry or with mustard seed extract presented relatively lower counts of LAB as small terpenoids and phenolic compounds (antimicrobial agents) are common in the alcohol extracts. Insignificant reductions of LAB counts were observed in the sample with AW and rosemary extract added after storing. Potentially pathogenic bacteria (Coagulase positive cocci, Salmonella, L. monocytogenes) were absent in all samples both after ripening and after the storage period. In all organic sausage samples after ripening, the growth of Enterobacteriaceae was similar compared to control (Table 5). An exception was the sample with AW and rosemary extract addition in which the lowest level of Enterobacteriaceae was noted ( $\left.\log 0.5 \mathrm{cfu} \mathrm{g}^{-1}\right)$. Djenane et al. (2002) found similar results showing that rosemary reduced the count of psychrotrophic bacteria significantly and prolonged shelf life by 10 days compared to control. After 180 days of chilling storage, the growth of Enterobacteriaceae was inhibited in all study samples. Organic dry fermented sausage is a good substrate for spoilage and pathogenic microorganisms because of its absence of curing agents and high nutrient contents (Zhang et al., 2009). Hasapidou and Savvaidis (2011) proved that the addition of herbs and spices (oregano, rosemary, clove, sage etc.) inhibited the growth of several food borne pathogens including Salmonella, E. coli, S. aureus, L. monocytogenes and S. flexneri.
Table 5 - Number (log cfu $\mathrm{g}^{-1}$ ) of lactic acid bacteria and Coagulase positive cocci, L. monocytogenes, Salmonella and Enterobacteriaceae after 0 and 180 days of chilling storage.

\begin{tabular}{lcccccc}
\hline [log cfu g-1] & Storage period & C & AW & R & J & M \\
\hline \multirow{2}{*}{ Lactic acid bacteria } & 0 & 7.51 & 7.64 & 7.58 & 7.64 & 7.62 \\
& 180 & 7.36 & 7.51 & 7.52 & 6.18 & 6.41 \\
Coagulase positive cocci & 0 & N.D. & N.D. & N.D. N.D. N.D. \\
& 180 & N.D. & N.D. & N.D. N.D. N.D. \\
Salmonella & 0 & N.D. & N.D. & N.D. N.D. N.D. \\
& 180 & N.D. & N.D. & N.D. N.D. N.D. \\
L. monocytogenes & 0 & N.D. & N.D. & N.D. N.D. N.D. \\
& 180 & N.D. & N.D. & N.D. N.D. N.D. \\
Enterobacteriaceae & 0 & 1.49 & 1.50 & 0.50 & 1.39 & 1.50 \\
& 180 & $<10$ & $<10$ & $<10<10<10$ \\
\hline
\end{tabular}

N.D. - not detected; $C=$ control, $A W=$ acid whey, $R=$ rosemary, $\mathrm{J}=$ juniper berries, $M=$ mustard seed.

\section{Quantitative descriptive analysis}

Figures 2 A, B, C show the results of the descriptive sensory analysis of the sausage after 180 days of storage. The assessors described the sausage as having meat part color on the cross sectional appearance ranging from $8.39 \mathrm{c.u}$. for AW sample to $7.10 \mathrm{c.u}$. for $\mathrm{C}$ sample. The fat color was between 4.50 c.u. and 8.39 c.u. for AW sample and $\mathrm{C}$ sample respectively. There were no significant differences $(p>0.05)$ between compactness slice and juiciness between samples. Significant lower rancid and metallic odor $(p<0.05)$ was found in $\mathrm{M}$ treatment compared to other samples probably because of their high ability to reduce Fe(III) to Fe(II) (reducing power 4.32). However, significantly higher acid odour $(p<0.05)$ was noted by assessors in the sample with mustard seed extract and acid whey. The highest rancid flavour was noted in two samples with acid whey only (2.34 c.u.) and in the sample with acid whey and juniper berry extract (3.28 c.u.). These results are in agreement with CD and TBARS value measurements (Table 4) which indicated the highest level of oxidation process in these samples. Significantly $(p<0.05)$ lower rancid odor 
A

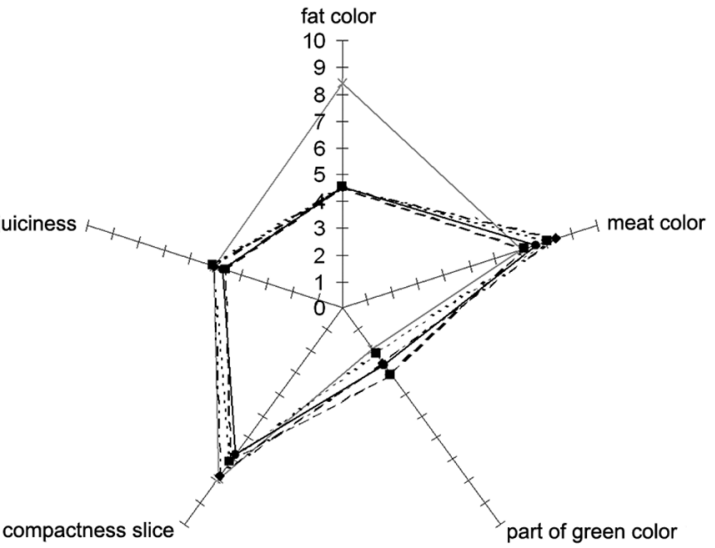

B

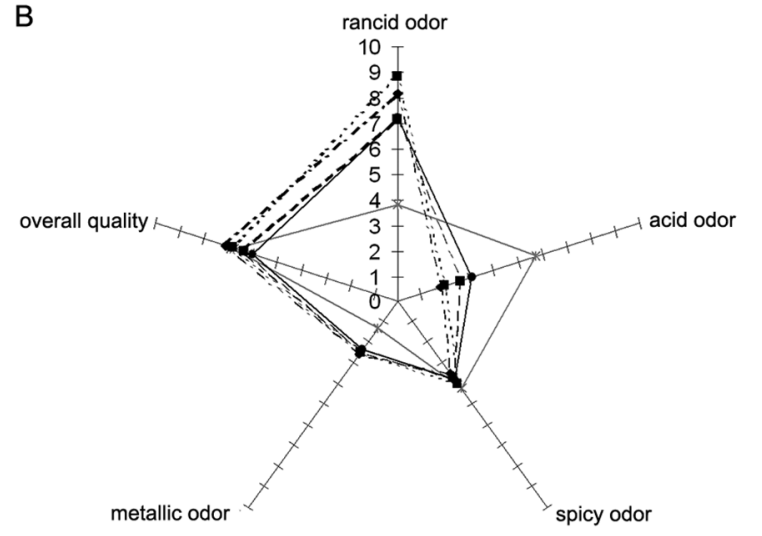

C

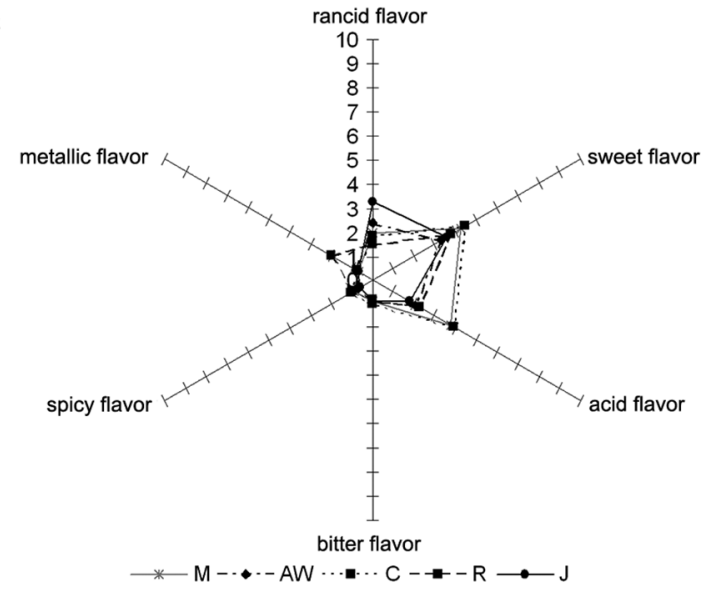

Figure 2 - Influence of acid whey with plant extract combination on odor and overall quality (A), appearance (B) and flavour (C) of uncured fermented sausage after 180 days of storage period. C = control, AW = acid whey, $\mathrm{R}=$ rosemary, $\mathrm{J}=$ juniper berries, $\mathrm{M}$ $=$ mustard seed.

$(p<0.05)$, (7.14) and rancid flavor (1.48) was observed for sample R compared with control sample with curing salt $(\mathrm{C})$. The low level of these attributes proved the antioxidant properties of the mixture of AW-rosemary, which confirmed the lower primary (CD concentration $\sim 0.48-0.48 \mu \mathrm{mol} \mathrm{mg}^{-1}$ ) and secondary (TBARS values 0.41-1.02 $\mathrm{mg} \mathrm{MDA} \mathrm{kg}^{-1}$ ) lipid oxidation products in $\mathrm{R}$ treatment during storage and the highest antioxidant activity $(\%)$ against ABTS + radicals $(\sim 85.45)$. There were no significant differences $(p>0.05)$ between attributes such as, for example, sweet flavor, bitter flavor, and spicy and metallic flavor between treatments. The assessors described the sausages as having intense acid flavor, ranging from 3.93 c.u. for control to 1.79 for the J sample. The overall quality ranged from $7.1 \mathrm{c}$.u. for AW to 6.0 c.u. for the J sausage. It is surprising that the sample with acid whey had overall quality higher than control with curing salt. The panel found both the control and $M$ sample equally acceptable (6.8 c.u.). The high quality of the $M$ sample was probably affected by the intensity of visible fat color which was whiter compared with other samples and the rancid odor and flavor which was less intense compared to other treatments.

\section{Conclusion}

According to the results obtained, uncured sausages can be considered as shelf-stable at room temperature. The addition of AW in combination with rosemary extract or mustard seed $(0.03 \%)$ can substitute for the curing agent in fermented sausage without having a negative impact on product quality (sensory attributes: rancid and metallic odor and flavor) and safety (CD and TBARS values, microbiological analysis) during 180 days of vacuum storage. The results of fatty acids composition measurements suggested that both the AW and rosemary extract when added to uncured sausage were able to protect PUFA and MUFA against the oxidation process in a similar way to to curing salt. The use of AW together with rosemary or mustard seed extract may offer meat industries the opportunity to produce organic uncured meat product with improved quality and safety during 180 days of storage. Despite the fact that the sample with acid whey had the worst oxidative stability level (high CD and TBARS values) during storage, the panel of assessors found the overall quality of this treatment higher when compared to other samples, probably because rancidity is indispensable the creation of characteristic odor and flavor of fermented meat products which did not influence the panel's acceptance. Incorporation of acid whey with mustard seed or rosemary extract on it will have a threefold effect on the product: high quality (sensory acceptance), health benefit (elimination of nitrite and nitrate from meat products) and safety (improved microbiological and oxidative stability).

\section{Acknowledgements}

The research presented in this paper was supported by the Polish Ministry of Agriculture and Rural Development grant, number PKre-029-29-29/13(688). 


\section{References}

Association of Official Analytical Chemists - International [AOAC]. 2005. Official Methods of Analysis. 18ed. AOAC, Gaithersburg, MD, USA.

Djenane, D.; Sanchez-Escalante, A.; Beltran, J.A.; Roncales, P. 2002. Ability of a-tocopherol, taurine and rosemary, in combination with vitamin $\mathrm{C}$, to increase the oxidative stability of beef steaks packaged in modified atmosphere. Food Chemistry 76: 407-415.

Hernández-Hernández, E.; Ponce-Alquicira, E.; Jaramillo-Flores, M.E.; Legaretta Guerrero, I. 2009. Antioxidant effect rosemary (Rosmarinus officinalis L.) and oregano (Origanum vulgare L.) extracts on TBARS and colour of model raw pork batters. Meat Science 81: 410-417.

Hasapidou, A.; Savvaidis, I.N. 2011. The effects of modified atmosphere packaging, EDTA and oregano oil on the quality of chicken liver meat. Food Research International 44: 27512756.

International Organization for Standardzation [ISO]. 1998. ISO 13299.2. Sensory Analysis - Methodology - General Guidance for Establishing a Sensory Profile. ISO, Geneva, Switzerland.

International Organization for Standardzation [ISO]. 2003. ISO 6579. Microbiology of Food and Animal Feeding Stuffs. Horizontal Method for the Detection of Salmonella spp. ISO, Geneva, Switzerland.

International Organization for Standardization [ISO]. 2002. ISO 15214. Microbiology of Food and Animal Feeding Stuffs. Horizontal Method for the Enumeration of Mesophilic Lactic Acid Bacteria. Colony- Count Technique at $30^{\circ} \mathrm{C}$. ISO, Geneva, Switzerland.

International Organization for Standardization [ISO]. 2000. ISO 11290-2. Microbiology of Food and Animal Feeding Stuffs. Horizontal Method for the Detection and Enumeration of Listeria monocytogenes. Part 2 - Enumeration Method. ISO, Geneva, Switzerland.

International Organization for Standardization [ISO]. 2005. ISO 21528-2. Microbiology of Food and Animal Feeding Stuffs. Horizontal Method for the Detection and Enumeration of Enterobacteriaceae. Colony- Count Technique. ISO, Geneva, Switzerland.

International Organization for Standardization [ISO]. 1999. ISO 6888. Microbiology of Food and Animal Feeding Stuffs. Horizontal Method for the Enumeration of Coagulase Positive Staphylococci (Staphylococcus aureus and Other Species). Part I. Technique Using Baird-Parker Agar Medium. Part II. Technique Using Rabbit Plasma Fibrinogen Agar Medium. ISO, Geneva, Switzerland.

Karwowska, M.; Wójciak, K.M.; Dolatowski, Z.J. 2014. The influence of acid whey and mustard seed on lipid oxidation of organic fermented sausage without nitrite. Journal of Science Food and Agriculture 95: 628-634.

Lee, Mi-Ai; Choi, Ji-Hun; Choi, Yun-Sang; Han, Doo-Jeong; Kim, Hack-Youn; Shim, So-Yeon; Chung, Hae-Kyung; Kim Cheon-Jei 2010. The antioxidative properties of mustard leaf (Brassica juncea) kimchi extracts on refrigerated raw ground pork meat against lipid oxidation. Meat Science 84: 498-504.
Leistner, W.; Rodel, W.; Krispien, K. 1981. Microbiology of meat and meat products in high- and intermediate-moisture ranges. p. 855-916. In: Rockland, L.B.; Stewart, G.F. (eds.), Water activity: influences of food quality. Academic Press, New York, NY, USA.

Lesjak, M.M.; Bearaa, I.N.; Orčič, D.Z.; Petarb, K.N.; Simina, N.D.; Emilijaa, S.D.; Mimica-Dukić, N.M. 2014. Phytochemical composition and antioxidant, anti-inflammatory and antimicrobial activities of Juniperus macrocarpa Sibth. et Sm. Journal of Functional Food 7: 257-268.

Li, L.; Shao, J.; Zhu, X.; Zhou, G.; Xu, Xi. 2013. Effect of plant polyphenols and ascorbic acid on lipid oxidation, residual nitrite and $\mathrm{N}$-nitrosamines formation in dry-cured sausage. International Journal of Food Science \& Technology 48: 1157-1164.

Marra, A.I.; Salgado, A.; Prieto, B.; Carballo, J. 1999. Biochemical characteristics of dry-cured lacón. Food Chemistry 67: 33-37.

Manda, K.R.; Adams, C.; Ercal, N. 2010. Biologically important thiols in aqueous extracts of spices and evaluation of their in vitro antioxidant properties. Food Chemistry 118: 589-593.

Oyaizu, M. 1986. Studies on products of browning reaction. Antioxidative activities of products of browning reaction prepared from glucosamine. Japanese Journal of Nutrition 44: 307-314 (in Japanese, with abstract in English).

Pikul, J.; Leszczyński, D.E.; Kummerow, F.A. 1989. Evaluation of three modified TBA methods for measuring lipid oxidation in chicken meat. Journal of Agricultural and Food Chemistry 37: 1309.

Poli, G; Sottero, B.; Gargiulo, S.; Leonarduzzi, G. 2009. Cholesterol oxidation products in the vascular remodeling due to atherosclerosis. Molecular Aspects of Medicine 30: 180-189.

Rasooli, I. 2007. Food preservation: a biopreservative approach. Food 1: 111-136.

Re, R.; Pellegrini, N.; Pannala, A.; Yang, M.; Rice-Evans, C. 1999. Antioxidant activity applying an improved ABTS radical cation decolorization assay. Free Radical Biology \& Medicine 9: 12311237.

Ruiz, J.N.; Villanueva, N.D.M.; Favaro-Trindade, C.S.; ContrerasCastillo, C.J. 2014. Physicochemical, microbiological and sensory assessments of Italian salami sausages with probiotic potential. Scientia Agricola 71: 204-211.

Ščetar, M.; Kovačić, E.; Kurek, M.; Galić, K. 2013. Shelf life of packaged sliced dry fermented sausage under different temperature. Meat Science 93: 802-809.

Shah, M.A.; Don Bosco, S.J.; Mir, S.A. 2014. Plant extracts as natural antioxidants in meat and meat products. Meat Science 98: 21-33.

Shon, J.; Haque, Z.U. 2007. Antioxidative ability of native and thermized sour whey in oxidation-catalysed model system. International Journal of Dairy Technology 60: 143-149.

Šojić, B.V.; Petrović, L.S.; Mandić, A.I.; Sedej, I.J.; Džinić, N.R.; Tomović, V.M.; Jokanović, M.R.; Tasić, T.A.; Škaljac, S.B.; Ikonić P.R. 2014. Lipid oxidative changes in traditional dry fermented sausage Petrovská klobása during storage. Hemijska Industrija 68: 27-34.

Srinivasan, S.; Xiong, Y.L.; Decker, A. 1996. Inhibition of protein and lipid oxidation in beef heart surimi-like material by antioxidants and combinations of $\mathrm{pH}, \mathrm{NaCl}$, and buffer type in the washing media. Journal of Agricultural and Food Chemistry 44: 119-125. 
Stadnik, J.; Stasiak, D.M.; Dolatowski, Z.J. 2014. Proteolysis in dry-cured loins manufactured with sonicated pork and inoculated with Lactobacillus casei ŁOCK 0900 probiotic strain. International Journal of Food Science and Technology 49: $2578-2584$.

Tong, L.M.; Sasaki, S.; McClements, D.J.; Decker, E.A. 2000. Antioxidant activity of whey in a salmon oil emulsion. Journal of Food Science 65: 1325-1329.
Wójciak, K.M.; Karowska, M.; Dolatowski, Z.J. 2014. Use of acid whey and mustard seed to replace nitrites during cooked sausage production. Meat Science 96: 750-756.

Zhang, H.; Kong, B.; Xiong, Y.L.; Sun, X. 2009. Antimicrobial activities of spice extracts against pathogenic and spoilage bacteria in modified atmosphere packaged fresh pork and vacuum packaged ham slices stored at $4{ }^{\circ} \mathrm{C}$. Meat Science 81 : 686-692. 